\title{
ANALISIS KEBUTUHAN TENAGA REKAM MEDIS BERDASARKAN BEBAN KERJA DI BAGIAN PELAPORAN RUMAH SAKIT KHUSUS GINJAL RASYIDA TAHUN 2018
}

\author{
${ }^{1}$ Suheri parulian Gultom, ${ }^{2}$ Sopian \\ 1. Dosen APIKES Imelda, Jalan Bilal Nomor 52 Medan; ${ }^{2}$ Alumni APIKES Imelda \\ E-mail: ${ }^{1 .}$ suheriparuliangultom@gmail.com
}

\begin{abstract}
ABSTRAK
Rekam medis merupakan bagian penting dari sistem kesehatan rumah sakit menyediakan pelayanan yang kompleks, pelayanan gawat darurat, pusat ahli pengetahuan, teknologi dan berfungsi sebagai pusat rujukan. Untuk meningkatkan kepuasan pemakai jasa, rumah sakit harus senantiasa meningkatkan mutu pelayan sesuai dengan harapan pelanggan yang dapat dilakukan melalui peningkatan kualitas kerja. Tujuan penelitian ini adalah mengetahui kebutuhan tenaga rekam medis berdasarkan beban kerja di bagian pelaporan rumah sakit Rasyida. Jenis penelitian ini adalah deskriptif dan menggunakan metode WISN yang bertujuan untuk melihat gambaran yang terjadi di dalam suatu populasi tertentu menggunakan perhitungan beban kerja petugas rekam medis. Waktu penelitian ini dilaksanakan pada bulan Juli tahun 2018 di rumah sakit Khusus Ginjal Rasyida. populasi dan sampel sebanyak 5 orang, yaitu seluruh jumlah petugas rekam medis di bagian pelaporan rumah sakit Khusus Ginjal Rasyida. Berdasarkan hasil penelitian yang telah dilakukan, hasil kebutuhan tenaga rekam medis adalah sebanyak 1,428. Hal ini juga dapat dilihat dari beban kerja yang tinggi dan total kebutuhan SDM frekuensinya rendah. Diketahui bahwa jumlah petugas rekam medis di bagian pelaporan rumah sakit Khusus Ginjal Rasyida berjumlah 5 orang dan melalui perhitungan dengan metode WISN dibutuhkan 1 orang agar dapat memenuhi syarat untuk menjalankan pekerjaanya sesuai dengan permenkes No. 55 tahun 2013 Tentang Penyelenggaraan Pekerjaan Perekam Medis agar beban kerja di rumah sakit Khusus Ginjal Rasyida tidak tinggi sehingga rumah sakit tersebut mendapatkan petugas rekam medis yang bertanggung jawab agar beban kerja yang ada dapat cepat teratasi dengan baik.
\end{abstract}

Kata Kunci: Tenaga Rekam Medis, Sistem Pelaporan, Beban Kerja

\section{PENDAHULUAN}

Menurut Undang-undang RI No. 44 Tahun 2009, rumah sakit adalah institusi pelayanan kesehatan yang menyelenggaraka $\mathrm{n}$ pelayanan kesehatan perorangan secara paripurna yang menyediakan pelayanan rawat inap, rawat jalan dan gawat darurat. Salah satu pelayanan kesehatan di rumah sakit yang sangat dibutuhkan dan merupakan pintu masuk pelayanan kesehatan adalah rekam medis.

Rekam medis bertujuan untuk menunjang tercapainya tertib administrasi dalam rangka upaya peningkatan pelayanan kesehatan di rumah sakit, dimana tanpa adanya dukungan suatu sistem pengelolaan rekam medis yang baik dan benar, maka tertib administrasi di rumah sakit tidak akan berhasil sebagaimana yang diharapkan. Sedangkan tertib administrasi merupakan salah satu faktor yang menentukan upaya pelayanan kesehatan di rumah sakit.

Bagian pelaporan merupakan sub unit di instalasi rekam medis suatu rumah sakit dimana berfungsi dalam pengumpulan data, interpretasi, pengolahan ,penyajian dan pembuatan laporan rumah sakit .Untuk melaksanakan pekerjaan pelaporan di unit rekam medis rumah sakit harus memiliki tenaga rekam medis yang memenuhi standar dilihat dari kuantitas maupun kualitasnya. Tenaga rekam medis di bagian pelaporan harus mumpuni dan kompeten di bidangnya 
masing-masing, sehingga hasil pelaporan data bermutu dan dapat dipertanggung jawabkan.

Perencanaan sumber daya manusia merupakan fungsi utama yang harus dilaksanakan oleh setiap organisasi serta harus menjadi fokus perhatian sehinga langkah-langkah yang diambil oleh manajemen menjadi tepat guna, lebih menjamin bahwa di dalam organisasi tersedia tenaga kesehatan yang tepat untuk menduduki jabatan dan pekerjaan yang tepat dalam waktu yang tepat dalam rangka mencapai suatu tujuan dan berbagai sasaran yang telah ditetapkan. Salah satu bentuk perencanaan sumber daya manusia kesehatan adalah perencanaan tenaga rekam medis.

Satu diantara pelayanan terpenting di rumah sakit terdapat pada pelayanan rekam medis yang dimulai dari pendaftaran, pendistribusian rekam medis, pengembalian rekam medis, assembling, koding, indeksing, analisa, pelaporan serta penyimpanan rekam medis. Dalam upaya peningkatan mutu pelayanan di rumah sakit, perlu adanya dukungan dari berbagai faktor, antara lain adalah faktor tersedianya tenaga yang cukup, berkompeten dan profesional.

Keberhasilan pelayanan rekam medis di bagian pelaporan rumah sakit didukung oleh sumber daya manusia yang mumpuni. Untuk mencapai visi dan misi rumah sakit, keterampilan dan kemampuan sumber daya manusia sangat diperlukan untuk membuat pelaporan yang akuntabilitas. Agar tercapai pelayanan rekam medis yang mengikuti kaidah tertib administrasi yang baik, rumah sakit perlu didukung oleh suatu pelaporan rekam medis yang baik. Pelaporan rekam medis membutuhkan tenaga yang kompeten di bidang rekam medis.

Menurut survey pendahuluan, jumlah kunjungan pasien di rumah sakit Khusus Ginjal Rasyida pada tahun 2017 adalah 64. 678 terdiri dari pasien rawat jalan 49.716 dan pasien rawat inap 14. 962 orang. Tenaga rekam medis yang bekerja di bagian pelaporan berjumlah 5 orang. Pendidikan tenaga rekam medis, yaitu D3 rekam medis 3 orang dan SLTA 2 orang. Pelatihan tenaga rekam medis pada tahun 2017 terdapat 2 orang. Diketahui juga bahwa tenaga rekam medis yang terlambat masuk kerja pada bulan Mei 2018 rata-rata keterlambatan 7 hari.

Berdasarkan observasi yang dilakukan peneliti, tenaga rekam medis di bagian pelaporan mempunyai tugas dalam pengump ulan data, analisa data, statistik dan pelapora n. Petugas rekam medis membuat laporan int ernal berupa: (1) jumlah kunjungan pasien, (2) jumlah pasien meninggal, jumlah pasien baru dan lama, (3) 10 besar penyakit dan (4) Indikator mutu pelayanan rumah sakit. Seda ngkan pelaporan eksternal yang ditujukan ke Dirjend Yanmed Depkes RI, Dinas Kesehata n Propinsi Sumatera Utara dan Dinas Keseh atan Kab/Kodya Medan. Pelaporan eksternal dilakukan secara online dengan Sistem Informasi Rumah Sakit (SIRS). Masalah lainnya di bagian pelaporan rumah sakit Rasyida adalah terus bertambahnya jumlah kunjungan pasien pertahunnya, sehingga beban kerja tenaga rekam medis bertambah khususnya di bagian pelaporan.

Penelitian yang dilakukan oleh Fitri (2015), tentang analisis kebutuhan tenaga rekam medis dengan metode WISN di Rumah Sakit, hasil penelitian didapatkan jumlah tenaga pada saat ini berjumlah 6 orang dengan latar belakang pendidikan D3 Rekam medis dan SLTA sederajat. Total waktu kerja tersedia dalam setahun adalah 281 hari/tahun dan $1967 \mathrm{jam} / \mathrm{tahun}$ atau 118.020 menit/tahun. Standar beban kerja tenaga rekam medis yang paling tinggi adalah pada pembuatan laporan statistik rumah sakit dan yang terendah registrasi pasien rawat jalan dan rawat inap dengan standar kelonggaran 0,14 . Jumlah tenaga rekam medis yang dibutuhkan berdasarkan perhitungan WISN adalah sebanyak 11 orang dan rasio WISN sebesar 0,54 artinya $54 \%$ kebutuhan tenaga telah terpenuhi dan terdapat kekurangan 5 orang tenaga. Kesimpulan Berdasarkan perhitungan WISN, dibutuhkan jumlah tenaga rekam medis sebesar 11 orang. Hal ini menunjukkan bahwa terdapat kekurangan tenaga sebanyak 5 orang

Penelitian yang dilakukan oleh Muthom imah (2015), tentang Analisis Kebutuhan Tenaga Kerja Berdasarkan Beban Kerja Unit 
Rekam Medis Rumah Sakit. Adapun hasil Penelitian didapatkan jumlah petugas assembling dengan standar beban kerja sebanyak 27.669,76 menit dibutuhkan sebanyak 4 petugas, petugas koding BPJS Rawat Jalan dengan standar beban kerja sebanyak 47.506,73 menit dibutuhkan sebanyak 4 petugas, petugas koding BPJS Rawat Inap dengan standar beban kerja sebanyak 22.542,7 menit dibutuhkan sebanyak 3 petugas, petugas filing dengan standar beban kerja 15.534,73 menit dibutuhkan sebanyak 9 petugas, dan petugas analising/ reporting dengan standar beban kerja 613 menit dibutuhkan sebanyak 2 petugas.

Berdasarkan permasalahan di atas, maka penulis tertarik melakukan penelitian tentang "Analisis Kebutuhan Tenaga Rekam Medis Berdasarkan Beban Kerja di Bagian Pelaporan Rumah Sakit Khusus Ginjal Rasyida tahun 2018.

\section{METODE}

Jenis penelitian yang digunakan adalah penelitian deskriptif dengan metode observasi dan wawancara dengan menggunakan pendekatan cross sectional yang bertujuan untuk mengetahui bagaimana kebutuhan tenaga rekam medis berdasarkan beban kerja di bagian pelaporan rumah sakit Rasyida tahun 2018. Lokasi penelitian ini dilakukan di rumah sakit Rasyida. Penelitian ini dilakukan pada bulan Maret sampai dengan Juli 2018.

Populasi pada penelitian ini adalah hasil perhitungan prediksi kunjungan 2018 dan seluruh petugas rekam medis di bagian pelaporan rumah sakit Rasyida tahun 2018 berjumlah 5 orang. Sampel dalam penelitian ini adalah seluruh populasi dijadikan sampel berjumlah 5 orang. Teknik sampling yang digunakan dalam penelitian ini adalah total sampling, dimana semua anggota populasi digunakan sebagai sampel yaitu petugas unit rekam medis di bagian pelaporan rumah sakit Rasyida tahun 2018.

\section{HASIL}

Berdasarkan penelitian yang dilakukan mengenai "Analisis Kebutuhan Tenaga Rekam Medis Berdasarkan Beban Kerja di Bagian Pelaporan Rumah Sakit Khusus Ginjal Rasyida Tahun 2018", adalah kurangnya petugas rekam medis di bagian pelaporan karena tidak sebanding dengan jumlah kunjungan pasien yang datang berobat terhitung dari bulan Januari Desember 2017, dimana pasien rawat inap berjumlah 14.962 orang dan pasien rawat jalan berjumlah 49.716 orang.

Gambaran Jumlah Tenaga Rekam Medis di Bagian Pelaporan Rumah Sakit Khusus Ginjal Rasyida tahun 2018.

1. Jumlah tenaga rekam medis di bagian pelaporan rumah sakit Rasyida berdasarkan wawancara dan observasi berjumlah 5 orang. Pendidikan D3 rekam medis berjumlah 3 orang dan SLTA berjumlah 2 orang.

2. Uraian tugas di Bagian Pelaporan Instalasi

Rekam Medis

Berdasarkan hasil studi dokumentasi uraian tugas tertulis, yang berlaku di bagian Pelaporan adalah :

a. Rekapitulasi jumlah kunjungan pasi en poliklinik

b. Rekapitulasi jumlah kunjungan pasi en gawat darurat

c. Rekapitulasi jumlah kunjungan pasi en rawat jalan

d. Rekapitulasi jumlah kunjungan pasi en rawat inap

e. Rekapitulasi jumlah pasien meningg al

f. Rekapitulasi jumlah pasien baru dan lama

g. Rekapitulasi 10 penyakit terbesar

h. Membuat indikator mutu rumah sakit

i. Laporan secara online dengan program SIRS

Perencanaan Kebutuhan Tenaga Rekam Medis Berdasarkan Beban Kerja di Bagian Pelaporan Rumah Sakit Khusus Ginjal Rasyida

Perencanaan kebutuhan tenaga rekam medis di bagian pelaporan rumah sakit Rasyida dengan menggunakan metode Work 
Load Indicator Staff Nedded (WISN), sebagai berikut :

Tabel 1. Waktu Kerja Tersedia di Bagian Pelaporan RSK Rayida tahun 2018

\begin{tabular}{ccc}
$\begin{array}{c}\text { KO } \\
\text { DE }\end{array}$ & FAKTOR & $\begin{array}{c}\text { KETERANGA } \\
\text { N }\end{array}$ \\
\hline A & Hari Kerja & 284 Hari/Tahun \\
\hline B & $\begin{array}{c}\text { Cuti } \\
\text { Tahunan }\end{array}$ & 7 Hari/Tahun \\
\hline C & $\begin{array}{c}\text { Pendidikan } \\
\text { dan } \\
\text { Pelatihan }\end{array}$ & 3 Hari/Tahun \\
\hline D & $\begin{array}{c}\text { Hari Libur } \\
\text { Nasional }\end{array}$ & 12 Hari/Tahun \\
\hline E & $\begin{array}{c}\text { Ketidakhadir } \\
\text { an Kerja }\end{array}$ & 5 Hari/Tahun \\
\hline F & $\begin{array}{c}\text { Waktu Kerja } \\
\text { 8 Jam/Hari }\end{array}$ \\
\hline \multirow{2}{*}{$\begin{array}{c}\text { Waktu Kerja } \\
\text { Tersedia }\end{array}$} & 2056 Jam/Tahun \\
\cline { 2 - 3 }$\left\{\begin{array}{c}\text { 1A-(B+C+D+E) } \\
\text { xF }\}\end{array}\right.$ & Menit/Tahun \\
\hline \multirow{2}{*}{ Hari Kerja Tersedia } & 257 Hari/Tahun
\end{tabular}

Sumber: Unit Rekam Medis RSK Rasyida Uraian perhitungan sebagai berikut :

a. Untuk hari kerja tersedia

Seluruh Kategori SDM :

$$
\{284-(7+3+12+5)\}
$$

$=257$ Hari Kerja/Tahun

b. Waktu Kerja Tersedia

Seluruh Kategori SDM :

257 (Hari/Tahun) x 8 Jam/Hari

$=2056 \mathrm{Jam}$ Kerja/Tahun

\section{Menetapkan Unit Kerja Dan Ketegori SDM}

Berdasarkan struktur organisasi bagian rekam medis rumah sakit Rasyida ,membuat perencanaan unit kerja dan kategori bagian rekam medis yaitu petugas bagian pelaporan berjumlah 5 orang.

\section{Standar Beban Kerja Per SDM Pada Bagian Pelaporan}

Standar beban kerja adalah volume/kuantitas beban kerja selama satu tahun per kategori SDM. Standar beban kerja untuk suatu kegiatan pokok disusun berdasarkan waktu yang dibutuhkan untuk menyelesaikannya (rata-rata waktu) dan waktu yang tersedia per tahun yang dimiliki oleh masing-masing kategori tenaga.

Standar Beban Kerja yang ada di rumah sakit khusus ginjal Rasyida di peroleh berdasarkan hasil perencanaan yang dilakukan oleh pihak rumah sakit, karena sistem yang digunakan sudah komputerisasi maka disesuaikan dengan kegiatan yang dilakukan pada saat ini, Standar Beban Kerja yang ada adalah sebagai berikut :

Tabel 2. Standar beban kerja tenaga rekam medis di bagian pelaporan RSK Rasyida

\begin{tabular}{clc}
\hline Unit kerja & \multicolumn{1}{c}{ Kegiatan pokok } & $\begin{array}{c}\text { Rata-Rata } \\
\text { Waktu }\end{array}$ \\
\hline \multirow{2}{*}{ Pelaporan Berkas } & 1. Melakukan sensus harian & 2,5 \\
Rekam Medis & 2. Mengumpulkan data & 2 \\
& 3. Merekapitulasi data & 2 \\
& 4. Menginput data pada software SIRS & 1 \\
& 5. Laporan bulanan & 2 \\
& a. Laporan 10 besar penyakit rawat jalan & 2 \\
& b.Laporan 10 besar penyakit rawat inap & 2 \\
& c.Laporan bulanan indikator mutu pelayanan & 1 \\
& 6. Pembuatan surat keterangan medis & 1 \\
& 7. Klaim BPJS & 1 \\
& a. Klaim BPJS rawat jalan & 16.5 \\
\hline
\end{tabular}




\section{Sumber:Hasil pengamatan dengan objek petugas pelaporan}

Menghitung Standar Beban Kerja Bagian Pelaporan RSK Rasyida:

Dik : a. Waktu Kerja Tersedia $=124320$

Menit/Tahun

b. Rata-Rata Waktu = 16.5 Menit

Dit : Standar Beban Kerja?

Jawab : Standar Beban Kerja

$=\underline{\text { Waktu Kerja Tersedia }}$

Rata-Rata Waktu per Kegiatan pokok

$=\underline{124320}$

16,5

$=7534$

\section{Standar Kelonggaran Per SDM di Bagian \\ Pelaporan}

Penyusunan standar kelonggaran bertujuan untuk memperoleh faktor kelonggaran tiap kategori SDM meliputi jenis kegiatan dan kebutuhan waktu untuk menyelesaikan suatu kegiatan yang tidak terkait langsung atau dipengaruhi tinggi rendahnya kualitas atau jumlah kegiatan pokok/pelayanan. Penyusunan faktor kelonggaran dapat dilaksanakan melalui pengamatan dan wawancara kepada tiap kategori tentang: kegiatan-kegiatan yang tidak terkait langsung dengan pelayanan pada pasien, misalnya rapat, penyusunan laporan kegiatan, menyusun kebutuhan bahan habis pakai; frekuensi kegiatan dalam suatu hari, minggu, bulan; serta waktu yang dibutuhkan untuk menyelesaikan kegiatan.

Standar kelonggaran yang ada di Bagian Pelaporan RSK Rasyida di sesuaikan dengan kegiatan-kegiatan yang ada, khususnya untuk bagian pelaporan memiliki standar kelonggaran adalah sebagai berikut:

Table 3. Standar Waktu Kelonggaran

\begin{tabular}{|c|c|c|c|c|c|}
\hline $\begin{array}{c}\text { Nama } \\
\text { Kegiatan }\end{array}$ & $\begin{array}{c}\text { Frekuensi } \\
\text { (Tahun) }\end{array}$ & Waktu (Jam) & $\begin{array}{l}\text { Jumlah } \\
\text { (menit) }\end{array}$ & $\begin{array}{c}\text { Waktu } \\
\text { Kerja } \\
\text { Tersedia } \\
\end{array}$ & SKI \\
\hline \multicolumn{6}{|c|}{ Perekam Medis } \\
\hline Kegiatan & \multirow{2}{*}{12} & \multirow{2}{*}{120} & \multirow{2}{*}{1440} & \multirow{2}{*}{124320} & \multirow{2}{*}{0.012} \\
\hline Perhimpunan & & & & & \\
\hline Narasumber & 2 & 120 & 240 & 124320 & 0.002 \\
\hline Rapat BPJS & 12 & 60 & 720 & 124320 & 0.002 \\
\hline Rapat Rutin & 12 & 60 & 720 & 124320 & 0.002 \\
\hline Pelatihan & \multirow[b]{2}{*}{3} & \multirow[b]{2}{*}{120} & \multirow[b]{2}{*}{360} & \multirow[b]{2}{*}{124320} & \multirow[b]{2}{*}{0.045} \\
\hline $\begin{array}{l}\text { Rekam } \\
\text { Medis }\end{array}$ & & & & & \\
\hline Seminar & 2 & 630 & 1260 & 124320 & 0.01 \\
\hline $\begin{array}{c}\text { Laporan } \\
\text { Sesuai } \\
\text { Permintaan } \\
\end{array}$ & 20 & 60 & 1200 & 124320 & 0.01 \\
\hline Adm BPJS & 255 & 60 & 15300 & 124320 & 0.123 \\
\hline $\begin{array}{l}\text { Pelatihan } \\
\text { Lain }\end{array}$ & 2 & 220 & 440 & 124320 & 0.007 \\
\hline
\end{tabular}

\section{Sumber : Unit Rekam Medis RSK Rasyida}

Untuk perhitungannya sebagai berikut :

Dik : Rata-rata waktu (jam) $=161$ jam/tahun (Kegiatan Perhitungan) Waktu Kerja Tersedia $=2056$
Dit : Standar Kelonggaran?

Jwb: Standar Kelonggaran Rata Rata per faktor kelonggaran Waktu Kerja Tersedia

$$
=\frac{161}{2056}=0.078
$$




\section{Kebutuhan SDM di Bagian Pelaporan}

Dalam perhitungan kebutuhan SDM dibutuhkan sumber data yang diperoleh dari langkah-langkah sebelumnya dan kuantitas kegiatan pokok tiap unit kerja selama kurun waktu satu data-data yang diperoleh dari langkah-langkah sebelumnya seperti data kegiatan pelayanan rawat jalan, rawar inap, standar beban kerja, standar kelonggaran merupakan data untuk perhitungan kebutuhan SDM di setiap unit kerja atau sub unit kerja penyimpanan rekam medis. Sumber data yang diperlukan untuk menghitung SDM per unit kerja salah satunya adalah Kuantitas Kegiatan Pokok yang dilakukan di unit rekam medis adalah sebagai berikut :

\section{Kuantitas Kegiatan Pokok RSK Rasyida} Medan

Tabel 4. Kuantitas Kegiatan Pokok

\begin{tabular}{|c|c|c|c|}
\hline No & $\begin{array}{c}\text { Kategori } \\
\text { SDM }\end{array}$ & $\begin{array}{c}\text { Kegiatan } \\
\text { Pokok }\end{array}$ & $\begin{array}{c}\text { Frekue } \\
\text { nsi }\end{array}$ \\
\hline \multirow{2}{*}{1} & \multirow{2}{*}{$\begin{array}{l}\text { Perekam } \\
\text { Medis }\end{array}$} & $\begin{array}{l}\text { Rawat } \\
\text { jalan }\end{array}$ & 27583 \\
\hline & & Rawat inap & 6345 \\
\hline
\end{tabular}

Maka untuk perhitungannya bisa dilihat pada tabel sebagai berikut :

Tabel 5. Kebutuhan Sumber Daya Manusia

\begin{tabular}{llllll}
\hline No & Kategori SDM & Kegiatan Pokok & $\begin{array}{c}\text { Kuantitas } \\
\text { Kegiatan }\end{array}$ & $\begin{array}{c}\text { Standar } \\
\text { Beban Kerja }\end{array}$ & $\begin{array}{c}\text { Kebutuhan } \\
\text { SDM }\end{array}$ \\
\hline 1 & $\begin{array}{l}\text { PEREKAM } \\
\text { MEDIS }\end{array}$ & Rawat Jalan & 27583 & 22064 & 1.25 \\
\cline { 2 - 5 } & Rawat Inap & 6345 & 49728 & 0.13 \\
\hline SUB TOTAL KEBUTUHAN SDM & & & 1.38 \\
\hline STANDAR KELONGGARAN & & & 0.078 \\
\hline \multicolumn{2}{l}{ TOTAL KEBUTUHAN SDM } & & $\mathbf{1 . 4 5 8}$ \\
\hline
\end{tabular}

Berdasarkan rumus yang sudah di tentukan diatas kebutuhan SDM untuk tiap kegiatan pokok terlebih dahulu jumlahkan sebelum ditambahkan dengan standar kelonggaran yang ada di unit rekam medis, dan untuk proses perhitungannya :

Kebutuhan SDM petugas rekam medis

Sub Total Kebutuhan SDM

$=$ Kuantitas kegiatan pokok

Standar beban kerja + Standar

kelonggaran

$=\underline{27583}$

22604

$=1.22$

$=$ Kuantitas Kegiatan

Standar Beban Kerja

$=\frac{6345}{49728}$

$=0.13$

Jadi sub total kebutuhan SDM adalah

$=1.22+0.13$

$=1.35$

Standar Kelonggaran $=\mathbf{0 . 0 7 8}$

Jadi, Total Kebutuhan SDM

$=1.35+0.078$

$=1.428$

$=1$ orang
Jadi jumlah keseluruhan tenaga rekam medis yang dibutuhkan di bagian pelaporan adalah 1 orang.

Upaya Penyelesaian Masalah yang Dilakukan oleh Unit Rekam Medis di RSK Rasyida

Upaya yang dilakukkan oleh unit rekam medis RSK Rasyida dalam menyelesaikan masalah yang timbul adalah :

1. Meminta tambahan petugas pada pimpinan dengan standar beban kerja yang di alami petugas.

2. Menambah ilmu pengetahuan agar semakin lebih baik dengancara pelatihan dan seminar ataupun pendidikan formal.

\section{PEMBAHASAN}

Berdasarkan hasil penelitian yang telah dilakukan kebutuhan tenaga rekam medis di bagian pelaporan rumah sakit Rasyida adalah 1 orang. Hal ini juga dapat dilihat dari beban kerjanya tinggi dan total kebutuhan SDM frekuensinya rendah.

Berdasarkan pendidikan dapat dilihat dari tamatan D3 rekam medis berjumlah 3 
orang dan SLTA sebanyak 2 orang total keseluruhan 5 orang, hal ini berarti Rumah Sakit Rasyida masih membutuhkan tenaga perekam medis tamatan dari S1 Rekam Medis agar bisa menjalankan pekerjaanya sesuai dengan Permenkes No. 55 tahun 2013 tentang Penyelenggaraan Pekerjaan Perekam Medis agar petugas rekam medis di RSK Rasyida beban kerjanya tidak menumpuk, sehingga rumah sakit tersebut mendapatkan penambahan petugas rekam medis yang bertanggungjawab, yang lebih baik lagi agar beban kerja yang ada dapat cepat teratasi.

\section{KESIMPULAN}

1. Analisis kebutuhan tenaga rekam medis berdasarkan beban kerja di bagian pelaporan RSK Rasyida tahun 2018 dengan menggunakan metode Workload Indicator Of Staffing Needing (WISN), jumlah tenaga rekam medis di bagian pelaporan adalah 5 orang dan jumlah yang dibutuhkan adalah 1 orang.

2. Direktur RSK Rasyida, komite medis dan Kepala Instalasi Rekam Medis harus membuat kebijakan bahwa syarat kualifikasi petugas rekam medis telah mengikuti pendidikan atau pelatihan dasar dan mampu mengoperasikan komputer.

\section{DAFTAR PUSTAKA}

Arikunto S. (2010). Prosedur Penelitian Suatu Pendekatan Praktik, Yogyakarta: PT Rineka Cipta.

Azrul Azwar. (1989). Menjaga Mutu Pelayanan Kesehatan. Jakarta: Pustak a Sinar Harapan.
Gomes F. Kardososo. (2003). Manjemen Sumber Daya Manusia. Yogyakarta: Andi.

Hatta, Gemala (1985). Catatan medic dalam kedudukannya sebagai penunjang sistem Kesehatan Nasional, Edisi 13. Jakarta: Buletin medical record.

Hatta, Gemala. (2011). Pedoman Manajeme $n$ Informasi Kesehatan di Sarana Pelayanan Kesehatan. Jakarta: UIPRESS.

Hidayat.Syarifudin. (2011). Metodologi Penelitian. Bandung : Mandar Maju

Kepmenkes. (2004). Tentang pedoman peny usunan perencanaan SDM kesehata $n$ di Tingkat provinsi. Kab. Serta Rumah Sakit.

Muthomimah Imant, dkk. (2015). Analisis Kebutuhan Tenaga Kerja Berdasarkan Beban Kerja Unit Rekam Medis Rumah Sakit Islam Kendal Tahun 2015. 1-

Notoatmodjo, Soekidjo. (2012). Metodologi Penelitian Kesehatan. Jakarta: Rineka Cipta.

Peraturan Menteri Kesehatan Republik Indonesia Nomor: 269/MENKES/PE R/III/2008. Tentang Rekam Medis

Ratna. (2014). Analisis Kesehatan Kode Diagnosis Dan Tindakan Pasien Raw at Inap, Rawat Jalan. Yogyakarta: Universitas Gadjah Mada

Santoso, Tuni. (2013). Organization Design dan Job Analysis. Jakarta: Kompas Gramedia.

Sugiono. (2011). Metode Penelitian Adminis trasi, Bandung: Alfabeta.

Sulistyaningsih. (2011). Metodologi Penelitian Kebidanan: KuantitatifKualitatif Yogyakarta: Graha Ilmu.

Undang-undang Republik Indonesia Nomor 44 Tahun (2009) Tentang Rumah Sakit. 2009. Jakarta: s.l 